\title{
Priority Setting in Neurosurgery as Exemplified by an Everyday Challenge
}

\author{
George M. Ibrahim, Michael Tymianski, Mark Bernstein
}

\begin{abstract}
Background: The allocation of limited healthcare resources poses a constant challenge for clinicians. One everyday example is the prioritization of elective neurosurgical operating room (OR) time in circumstances where cancellations may be encountered. The bioethical framework, Accountability for Reasonableness (A4R) may inform such decisions by establishing conditions that should be met for ethically-justifiable priority setting. Objective: Here, we describe our experience in implementing A4R to guide decisions regarding elective OR prioritization. Methods: The four primary expectations of the A4R process are: (1) relevance, namely achieved by support for the process and criteria for decisions amongst all stakeholders; (2) publicity, satisfied by the effective communication of the results of the deliberation; (3) challengeability through a fair appeals process; and (4) Oversight of the process to ensure that opportunities for its improvement are available. Results: A4R may be applied to inform OR time prioritization, with benefits to patients, surgeons and the institution itself. We discuss various case-, patient-, and surgeon-related factors that may be incorporated into the decision-making process. Furthermore, we explore challenges encountered in the implementation of this process, including the need for timely neurosurgical decision-making and the presence of hospital-based power imbalances. Conclusion: The authors recommend the implementation of a fair, deliberative process to inform priority setting in neurosurgery, as demonstrated by the application of the A4R framework to allocate limited OR time.
\end{abstract}

RÉSUMÉ: La priorisation en neurochirurgie : exemple d'un défi quotidien. Contexte : L'allocation de ressources limitées en matière de soins de santé constitue un défi constant pour les cliniciens. Un exemple quotidien en est la priorisation du temps opératoire pour les cas électifs en neurochirurgie, dans des circonstances où des annulations peuvent survenir. Le cadre bioéthique, la responsabilité pour la raisonabilité (A4R), peut éclairer de telles décisions en établissant les conditions qui devraient être remplies pour une priorisation éthiquement justifiable. Objectif : Nous décrivons notre expérience de l'application de l'A4R pour guider les décisions concernant la priorisation du temps opératoire en neurochirurgie élective. Méthode : Les quatre principales attentes du processus A4R sont les suivantes : 1) la pertinence, établie notamment par le soutien pour le processus et les critères de décision de la part de toutes les parties prenantes ; 2) la publicité, réalisée par la communication efficace des résultats de la délibération ; 3) la possibilité d'appel par un processus équitable ; 4) la surveillance du processus afin de s'assurer de saisir les occasions de l'améliorer. Résultats : L'A4R peut être appliquée pour clarifier la priorisation du temps opératoire, ce qui bénéficie aux patients, aux chirurgiens et à l'institution elle-même. Nous discutons de différents facteurs relatifs aux cas, aux patients et aux chirurgiens qui peuvent être incorporés dans le processus décisionnel. De plus, nous explorons les défis rencontrés dans l'implantation de ce processus, dont le besoin de prendre des décisions neurochirurgicales en temps opportun et la présence de déséquilibre de pouvoir au sein du milieu hospitalier. Conclusion : Les auteurs recommandent l'implantation d'un processus de délibération juste pour clarifier la priorisation en neurochirurgie, comme nous l'avons démontré par l'application du cadre A4R pour l'allocation de temps opératoire limité en neurochirurgie.

Can J Neurol Sci. 2013; 40: 378-383

Challenges associated with resource limitations permeate virtually every aspect of contemporary healthcare systems. From the acquisition of timely diagnostics to the stratification of patients based on the urgency of their presentation, healthcare workers constantly form prioritization algorithms to assist in clinical decision-making. Priority setting, formerly known as rationing or resource allocation is necessary to safeguard patient safety and ensure the efficient functioning of healthcare systems. Several validated tools may inform such decision-making. For example, the Canadian Emergency Department Triage and Acuity Scale $^{1}$ may be used to evaluate urgency of emergency department visits and the Injury Severity Score $^{2}$ may be applied to the evaluation of trauma severity. The priority setting process, however, most commonly occurs implicitly and intuitively. For example, a surgeon may choose to cancel/defer an elective surgical case in order to allocate his/her operating room (OR) time towards a more urgent case.

Priority setting occurs across multiple levels, ranging from the individual clinician to the departmental, institutional and governmental levels. A hospital for instance may decide to allocate funds towards the purchase of a new MRI scanner to decrease diagnostic imaging waiting times instead of hiring additional nurses to increase bed capacity. In extreme

From the Division of Neurosurgery (GMI, MT, MB), Department of Surgery, Institute of Medical Science (GMI, MT), Department of Physiology (MT), Toronto Western Hospital Research Institute (MT), University of Toronto, Toronto, Ontario, Canada. Received October 4, 2012. Final Revisions Submitted December 10, 2012. Correspondence to: Mark Bernstein, Toronto Western Hospital, 399 Bathurst Ave, Toronto, Ontario, M5T 2S8, Canada. Email: mark.bernstein@uhn.ca. 
circumstances, such as pandemics crises or unforeseen disasters, hospitals must also efficiently prioritize human and material resources $^{3}$. On a systems level, resource allocation requires contractual agreement between the stakeholders, as the individuals involved in decision-making may have different and competing priorities. Moral disagreements regarding prioritization algorithms often arise as decisions are rarely unanimous and universally value-laden; therefore, an impartial, ethically-justifiable mechanism is necessary to maintain the legitimacy of the decision-making process.

A framework for priority setting has been proposed by Daniels and Sabin, the Accountability for Reasonableness (A4R) framework (Table 1$)^{4,5}$. Its premise is that individuals may disagree on the factors that are important in reaching a decision, but all are in agreement that the process itself should be fair. A4R asserts that organizations and/or individuals must be held accountable for the reasonableness of their decisions, by satisfying four primary expectations (or conditions): relevance, publicity/transparency, revision/challengability, and enforcement/ oversight. This framework may be elegantly applied to resource allocation in specific fields such as neurosurgery to ensure that the process is fair, deliberative and efficient.

Here, we present a simple, every-day example of the application of A4R as used by the Division of Neurosurgery at Toronto Western Hospital (TWH), Toronto, Ontario, Canada in order to fairly allocate a limited availability of operating room (OR) time. Accountability for Reasonableness is implemented to inform OR time allocation in circumstances where one or more case cancellations may be encountered due to a lack of inpatient beds or unavailability of nurses. We draw on our experience to discuss how satisfying the four expectations of the A4R framework successfully creates a fair and deliberative process for priority setting in neurosurgery. We find that establishing a mechanism to address such resource allocation challenges is superior to 'reactive' decision-making, which may differ from day to day or from individual to individual. We therefore propose that the application of this simple bioethical framework to neurosurgical decision-making may render the process more equitable and ethically justifiable.

\section{Cancellations of elective ORs: An everyday challenge For neurosurgeons}

Cancellation of elective OR time is a common challenge worldwide and has been described in numerous countries with discrepant healthcare systems ${ }^{6-15}$, with some groups reporting over $30 \%$ cancellation rates on the day of surgery. At our institution, we identified a $4 \%$ same-day cancellation rate within the Department of Surgery. The cancellation rate for neurosurgical ORs is less, at approximately 1\%. In several studies, it was determined that elective OR cancellations were mainly due to facility limitations, such as overrun of the previous surgery, as opposed to patient- or surgeon-related factors ${ }^{6,10-13}$. Unavailability of hospital beds is also reported as an important reason for elective OR cancellation ${ }^{7,16}$. Furthermore, large prospective multi-center studies identified that surgical services in university hospitals are significantly more likely to be cancelled than those in community hospitals ${ }^{17}$ and private hospitals are less likely to experience OR cancellations compared to public hospitals ${ }^{14}$.

Various methods have been previously suggested to attempt to mitigate elective OR cancellations. These include logistical changes to improve patient flow $^{18}$, as well as a quantitative algorithm to estimate OR duration in order to design more efficient schedules ${ }^{19,20}$. It has also been suggested that case sequences should be based on their probability of cancellation, however, these strategies have largely been found to be impractical and inaccurate, as unforeseen cancellations are, by their nature, difficult to predict ${ }^{21}$. Ultimately, a mechanism must be in place to guide OR prioritization decisions in circumstances where cancellations may be encountered.

Table 1: Application of accountability of reasonableness (A4R) for an illustrative example of prioritizing operating room schedule given cancellations

\begin{tabular}{|c|c|c|}
\hline $\begin{array}{l}\text { Framework } \\
\text { Expectation }\end{array}$ & Explanation & Application to Illustrative Example \\
\hline \multicolumn{3}{|l|}{ Relevance } \\
\hline & $\begin{array}{l}\text { The deliberative process is based on factors (i.e. } \\
\text { evidence or principles) that fair-minded people would } \\
\text { consider relevant given the systemic limitations. }\end{array}$ & $\begin{array}{l}\text { There was consensus on the importance of developing a priority setting } \\
\text { strategy to address elective OR cancellations among surgeons. A } \\
\text { reasonable list of factors to consider was created to facilitate the process. }\end{array}$ \\
\hline \multicolumn{3}{|c|}{ Publicity (Transparency) } \\
\hline & $\begin{array}{l}\text { The factors considered to reach a decision are } \\
\text { publically available, transparent, and open to the } \\
\text { scrutiny of all stakeholders. }\end{array}$ & $\begin{array}{l}\text { Communication of the OR prioritization schedule, as well as the criteria } \\
\text { that is used to make the decisions are sent via email to all the surgeons } \\
\text { daily. All first cases proceed, and a prioritized list of surgeons is created } \\
\text { in case of a bed shortage. }\end{array}$ \\
\hline \multicolumn{3}{|c|}{ Appeals/Revisions (Challengeability) } \\
\hline & $\begin{array}{l}\text { A process must be implemented, whereby individuals } \\
\text { may bring forth evidence to challenge the decision. }\end{array}$ & $\begin{array}{l}\text { Disputes are resolved informally. If the individual surgeons have any } \\
\text { concerns, they may discuss relevant factors and the OR prioritization } \\
\text { schedule can be adapted accordingly. }\end{array}$ \\
\hline \multicolumn{3}{|c|}{ Enforcement (Oversight) } \\
\hline & $\begin{array}{l}\text { Leaders must ensure that the above three expectations } \\
\text { are met }\end{array}$ & $\begin{array}{l}\text { The surgeon who maintains the process and sends out the emails is not } \\
\text { excluded from the process (i.e. leading by example). A second surgeon } \\
\text { reviews the process and maintains a database in order to ensure that it is } \\
\text { impartial and fair. }\end{array}$ \\
\hline
\end{tabular}




\title{
Start all first cases. After that:
}

\author{
Dr. Cushing 2nd case \\ Dr. Dandy 2nd case \\ Dr. Penfield 2nd case \\ Dr. Cushing 3rd case
}

Please feel free to challenge any of this. Transparency and opportunity to appeal are 2 of the $\mathbf{4}$ key elements of the modern bioethics framework for priority setting know as the accountability for reasonableness.

If there are extenuating circumstances (e.g. case is fairly urgent; patient was previously cancelled; etc) please let me know the day before.

DSU cases and inpatients in Neuro do not get prioritized. Inpatients needing an upgrade from medical or Neuro ward to NCCU or ICU enter the prioritization ladder with high priority.

\section{Some of the factors used in prioritizing}

Urgency of case

Case through Criticall

Case is volume funded

Patient was previously cancelled

Expected timing of end of first cases

Whether surgeon OR time has recently been affected

Surgeons' use of day surgery for eligible cases

Stereotactic case when frame has been put on in the morning

Total cases that will get done given different prioritization schemes

Figure: Typical correspondence distributed by e-mail to all 12 neurosurgeons and the two orthopedic spinal surgeons at TWH each day for the next day's OR. Elective ORs are prioritized in the event of possible bed shortages. The surgeons are invited to appeal the decisions, and are provided some of the factors taken into consideration when creating the list.

\section{Framework application to the prioritization of elective OR} schedule

At TWH, A4R was implemented as a framework to inform this deliberation process. On a daily basis, a neurosurgeon (M.B.) at the request of the Division Head, reviews the list of ORs that are scheduled for the following day, as well as the facility limitations. Several neurosurgical ORs proceed concurrently, and typically, each surgeon has several cases per day. Outpatient procedures, such as awake craniotomy and "simple" spine surgery, which are commonly performed at our institution $^{22-24}$ are not included in this review process as they are not inpatient-bed dependent. All first cases are planned to proceed as scheduled due to the high likelihood of availability of resources for those cases. A schedule is emailed to all neurosurgeons the evening prior to the OR day, listing the prioritization of second and subsequent surgeries that will proceed in the event of inadequate inpatient beds to accommodate all cases (Figure). Factors that are used in the prioritization algorithm are included in this correspondence (Table 2). Surgeons are made aware that they are able to appeal the decisions should they have compelling reasons to dispute the prioritization.

\section{Relevance}

The first expectation of the A4R framework is relevance, which is a requirement for reasonableness: the notion that decisions should be made on the basis of factors that the group of individuals a priori agree upon as relevant given the specific circumstances. This requirement was satisfied at our institution in two ways. Firstly, consensus was reached amongst neurosurgeons that a fair, deliberative process, such as the one informed by $\mathrm{A} 4 \mathrm{R}$ should be implemented at the institution. Although this may seem self-evident, formalization of such consensus ensures that all stakeholders are committed to upholding its expectations and agree that its ethical underpinnings are relevant under the given circumstances. At many neurosurgical centers, including TWH prior to the introduction of the current process, OR prioritization decisions were 'reactive', occurring only when a cancellation was imminent. This may be problematic as the deliberation process is 
limited by the timely need for a decision. As a result, a single individual (most often the neurosurgical division head or OR manager) is usually responsible for such decisions based on unclear or inconsistent considerations. Foreplanning for cancellations and creating a prioritization list in the event that they should occur was recognized as an important initiative, requiring an explicit ethically-justifiable process.

Secondly, all surgeons agreed upon the factors that should be taken into consideration when prioritizing elective OR schedules. A list of these factors is distributed with the prioritization list on a daily basis. The majority of these were formulated through informal discussions and intuition. For example, it is obvious that a sicker patient should have priority to the OR. Furthermore, compassionate considerations were also included. Two examples include: patients who traveled a longer distance to have the operation might have priority over those who did not; and those patients already cancelled once before receive higher priority. Resource-related prioritization factors were also considered, namely that patients who are volumefunded or those who came from other hospitals through a provincial urgent referral system (Criticall) may be prioritized higher. Prioritization of volume-funded or criticall cases is ethically justifiable only if it does not interfere with access for patients who are not in those priority categories. This is enabled by the fact that the hospital receives incremental resources for these patients, enabling the opening of more OR resources. Therefore, volume-funded and criticall patients do not displace others at the institutional level. Moreover, prioritization of these patients is ethically justified because volume funding is allocated to conditions that are either very serious (i.e. subarachnoid hemorrhage) or have unacceptable wait times (i.e. brain tumors), or both. A list of case-, patient-, surgeon- factors that may guide priority setting is presented in Table 2 . Additional factors may be proposed by any surgeon at any point in time in order to enrich the deliberation process.

\section{Publicity/Transparency}

This expectation pertains to effective communication of the decisions and the factors considered during deliberations to all stakeholders. At our institution, the prioritization list in case of cancellations is created and distributed a day prior to the OR time. This affords the individual surgeons the opportunity to review the schedule and ample time for appeals. Transparency in the process is also satisfied by publication of factors taken into consideration with the distributed OR list.

Certainly, a reasonable argument can be made that the patients themselves are stakeholders in the process, and have a right to access their prioritization rank should cancellations occur. Indeed, the importance of patient involvement in medical decision-making is increasingly recognized. For example, there has been an impetus to provide greater information to patients, such as data on the performance of individual surgeons (i.e. the surgeons' report card $)^{25,26}$. These arguments are justified by numerous ethical tenets, namely pertaining to patient autonomy and informed consent. Alternatively, as these system-level decisions pertain to healthcare resource allocation, they may contribute unnecessary to patient anxiety on the day of scheduled OR. At our institution, the neurosurgeons advocate on behalf of their patients should they have special considerations that should
Table 2: Factors that may be used in prioritizing cases

\begin{tabular}{l|l}
\hline Categories & Relevant Factors \\
\hline Case-Specific Factors \\
\hline & Urgency of Case \\
\hline & Case presents through Criticall \\
\hline & Case is volume funded \\
& $\begin{array}{l}\text { Expected length of case (i.e. maximum number of } \\
\text { cases that could get completed given different } \\
\text { prioritization schemes) }\end{array}$ \\
\hline & $\begin{array}{l}\text { Stereotactic neurosurgery case where frame has } \\
\text { already been placed on patient }\end{array}$ \\
\hline Patient-Specific Factors \\
\hline & Patient was previously cancelled \\
\hline & Patient arrived from out-of-town for OR \\
\hline Surgeon-Specific Factors \\
\hline & Other unique patient circumstances \\
\hline & Surgeon OR time recently affected \\
\hline & Other agreed-upon factors \\
\hline
\end{tabular}

be taken into account; therefore the prioritization list is not distributed to patients.

\section{Revision/Challengeability}

This expectation dictates that a mechanism should be instigated to provide opportunities to challenge the decision. Evidence should be brought forth to support a revision and if acceptable, the decision may be overturned. Multiple reasonable factors may be introduced to inform these decisions (Table 2). Revisions and appeals also enrich decision-making as previous decisions may be brought forth as precedents or may be themselves scrutinized, supplying opportunities to improve the process. Daniels and Sabin believe that over time, a "case-law" may therefore develop as a result of challenges to decisions ${ }^{27}$.

In most cases, the neurosurgeons challenge the prioritization decisions the day prior to the elective ORs once the tentative schedule has been distributed. Implementation of such a system may also improve OR efficiency, as final decisions regarding prioritizations are made well in advance of possible cancellations and all stakeholders are aware of their respective rank. If emergent cases arrive and elective cases must be cancelled as a result, precious OR time is not wasted considering the priority of cases that will proceed. Implementation of A4R may therefore promote responsible healthcare resource stewardship. Since implementing the A4R framework, the priority list has been challenged approximately once a month.

\section{Oversight}

A large survey evaluating fulfillment of the A4R expectations among Ontario hospital decision-makers found that the enforcement aspect was typically the least satisfied ${ }^{28}$. An additional study at our institution has also corroborated this finding ${ }^{29}$. We showed that although monitoring processes did indeed exist, they were not well-known to the stakeholders. Germane to the principles of quality assurance, oversight of any decision-making process cannot be understated, and this 
comprises the fourth expectation of A4R. This oversight process begins with the individual responsible for the creating and distributing the prioritization list. He/she must lead by example and be prepared to accept reasonable challenges to the prioritization schedule.

Numerous oversight options may be appropriate, as determined by consensus among the stakeholders. For example, individual surgeons may choose to have a rotating schedule whereby different individuals are responsible for priority setting. Alternatively, an auditing process may be implemented, whereby a third party (or parties) may review the prioritization lists over a given period of time to ensure that the process is equitable. At our institution, the head of neurosurgery or his delegate reviews the prioritization lists monthly to ensure that no surgeon is given preference over others.

\section{Discussion}

Here, we describe our experience in implementing the Accountability for Reasonableness (A4R) framework at a large quaternary neurosurgical centre to address the challenges of elective OR prioritizations in the event of unforeseeable cancellations. As the purpose of this framework is to hold decision-makers accountable for the reasonableness of their decisions, we have found that its implementation has resulted in a fair, and deliberative mechanism to inform resource allocation decisions. Central to this process is the realization that individuals may justifiably disagree on which factors are most important when prioritizing cases, but all must agree that goal of the process is to ensure fairness (i.e. protecting equality of opportunity). We propose that the explicit adoption and integration of this framework into neurosurgical priority setting will mitigate conflicts and facilitate the ethical allocation of limited resources.

We have found that such a system is superior to 'reactive' priority setting in circumstances where OR cancellations are unavoidable. From a patient perspective, it ensures that individuals are prioritized if medically sick or have been disadvantaged previously (i.e. previously cancelled). For physicians, the process itself is equitable, transparent and open to appeals. Therefore, fewer conflicts arise as a result as all physicians have equality of opportunity. Finally, from an institutional perspective, resources are rationed responsibly. The process allows precious OR time to be managed efficiently, thereby saving time and financial resources, as well as potentially avoiding further unnecessary OR cancellations.

The A4R is a versatile framework whose four expectations are recognizable and applicable across different levels of decision-making ${ }^{30}$. It has been effectively applied to numerous other contexts, including health distribution, bed allocation, district health management in low-resource settings, funding for innovative pharmaceuticals and priority setting during pandemics ${ }^{3,29,31-34}$. Lessons from these studies can also be applied to the neurosurgical priority setting process. For instance, one perceived challenge in applying the A4R in Tanzania was related to difficulties in fostering greater accountability and involvement among local actors and the need to deal with power asymmetries among the individual stakeholders $^{31}$. Similarly, the successful application of this framework in neurosurgery requires 'buy-in' from all the stakeholders and an explicit effort to decrease hospital-based power imbalances. In fact, it has been proposed that a fifth expectation should be incorporated into the A4R framework: empowerment ${ }^{35}$. This condition would require effective participation and minimization of power-differences in decisionmaking.

Empowerment is a challenging condition to meet in neurosurgical care. Firstly, the hospital system is hierarchical, with more senior or experienced individuals (i.e. department heads) possessing much of the decision-making authority. Surgeon seniority may cause conflicts among the group and discussions regarding ways to address these power imbalances should take place. Secondly, while appeals are an important expectation of $\mathrm{A} 4 \mathrm{R}$, the neurosurgical experience is unique in that decisions must be made rapidly and often with little time for deliberation ${ }^{35}$. Several factors suggested by Gibson and colleagues to empower stakeholders, including incorporating iterative decision-making processes, using a closed vote system, or extending the time of discussion are not feasible in neurosurgery. It remains important, however that stakeholders appreciate that dissent is welcome. Several solutions that have been applied at our institution include the distribution of the prioritization list a day in advance, to provide ample time for consideration of appeals.

The application of A4R has also extended beyond resource rationing to other areas of health policy to reduce inequalities. An example provided by Daniels and Sabin relates to how much priority should be given to those who are worse off if an intervention would be more beneficial to others who are better off $^{36}$. We have previously explored this topic as it relates to the use of palliative surgical procedures to achieve a reduction in seizure frequency in children with medically intractable epilepsy ${ }^{37}$. As such children have a lower margins of improvements in their quality of life, they risk having a lower priority placed on treatments that can improve their lives, the socalled "double jeopardy" 38-40. It has been suggested that implementation of $\mathrm{A} 4 \mathrm{R}$ applies a human rights approach to health ${ }^{41}$, which would take into consideration the respective benefit to marginalized or vulnerable patient groups.

Given the importance of scarce resource allocation, a versatile, adaptable, and ethical mechanism must be implemented to inform priority setting decisions. At our institution, we have found that the A4R renders this process more equitable and fair. It is expected that as demand on healthcare resources increases, the healthcare decision-makers will be increasingly held accountable for the reasonableness of their priorities. We propose that neurosurgical centers should apply an ethical framework, such as A4R to guide neurosurgical decision-making. Through the example of OR time allocation, we demonstrate that satisfaction of its primary expectations renders the process ethically-justifiable for all stakeholders.

\section{Conclusion}

Here, we describe our experience in applying the A4R framework to inform decision-making regarding $\mathrm{OR}$ prioritization in circumstances where cancellations may be encountered. We have found that satisfying the four primary expectations of A4R creates a fair, equitable, and ethicallyjustifiable process that holds individuals accountable to the 
standard of reasonableness and mitigates conflicts. Given the increasing strains on healthcare systems and specifically OR facilities, we propose that $\mathrm{A} 4 \mathrm{R}$ may be a robust framework to guide ethical resource allocation decisions.

\section{ACKNOWLEDGEMENT}

The authors acknowledge Dr. Chris Wallace who was the Neurosurgery Division Head when this system was introduced at TWH.

\section{REFERENCES}

1. Beveridge R, Ducharme J, Janes L, Beaulieu S, Walter S. Reliability of the Canadian Emergency Department triage and acuity scale: interrater agreement. Ann Emerg Med. 1999;34(2): $155-9$

2. Baker SP, O'Neill B, Haddon W, Jr, Long WB. The injury severity score: a method for describing patients with multiple injuries and evaluating emergency care. J Trauma. 1974;14(3):187-96.

3. Bell JA, Hyland S, DePellegrin T, Upshur RE, Bernstein M, Martin DK. SARS and hospital priority setting: a qualitative case study and evaluation. BMC Health Serv Res. 2004;4(1):36.

4. Daniels N, Sabin J. The ethics of accountability in managed care reform. Health Aff (Millwood). 1998;17(5):50-64.

5. Daniels N, Sabin J. Setting limits fairly: can we learn to share scarce resources? Oxford: Oxford University Press; 2002.

6. Chiu CH, Lee A, Chui PT. Cancellation of elective operations on the day of intended surgery in a Hong Kong hospital: point prevalence and reasons. Hong Kong Med J. 2012;18(1):5-10.

7. Mesmar M, Shatnawi NJ, Faori I, Khader YS. Reasons for cancellation of elective operations at a major teaching referral hospital in Jordan. East Mediterr Health J. 2011;17(8):651-5.

8. Lau HK, Chen TH, Liou CM, Chou MC, Hung WT. Retrospective analysis of surgery postponed or cancelled in the operating room. J Clin Anesth. 2010;22(4):237-40.

9. Haana V, Sethuraman K, Stephens L, Rosen H, Meara JG. Case cancellations on the day of surgery: an investigation in an Australian paediatric hospital. ANZ J Surg. 2009; 79(9):636-40.

10. Gonzalez-Arevalo A, Gomez-Arnau JI, delaCruz FJ, et al. Causes for cancellation of elective surgical procedures in a Spanish general hospital. Anaesthesia. 2009;64(5):487-93.

11. Garg R, Bhalotra AR, Bhadoria P, Gupta N, Anand R. Reasons for cancellation of cases on the day of surgery-a prospective study. Indian J Anaesth. 2009;53(1):35-9.

12. Schofield WN, Rubin GL, Piza M, et al. Cancellation of operations on the day of intended surgery at a major Australian referral hospital. Med J Aust. 2005;182(12):612-15.

13. Kumar R, Gandhi R. Reasons for cancellation of operation on the day of intended surgery in a multidisciplinary 500 bedded hospital. J Anaesthesiol Clin Pharmacol. 2012;28(1):66-9.

14. McIntosh B, Cookson G, Jones S. Cancelled surgeries and payment by results in the English National Health Service. J Health Serv Res Policy. 2012;17(2):79-86.

15. Argo JL, Vick CC, Graham LA, Itani KM, Bishop MJ, Hawn MT. Elective surgical case cancellation in the veterans health administration system: identifying areas for improvement. Am J Surg. 2009;198(5):600-6.

16. Robb WB, O'Sullivan MJ, Brannigan AE, Bouchier-Hayes DJ. Are elective surgical operations cancelled due to increasing medical admissions? Ir J Med Sci. 2004;173(3):129-32.

17. Schuster M, Neumann C, Neumann K, et al. The effect of hospital size and surgical service on case cancellation in elective surgery: results from a prospective multicenter study. Anesth Analg. 2011;113(3):578-85

18. Hovlid E, Bukve O, Haug K, Aslaksen AB, von Plessen C. A new pathway for elective surgery to reduce cancellation rates. BMC Health Serv Res. 2012;12(1):154.

19. Pandit JJ, Carey A. Estimating the duration of common elective operations: implications for operating list management. Anaesthesia. 2006; 61(8):768-76.
20. Pandit JJ, Tavare A. Using mean duration and variation of procedure times to plan a list of surgical operations to fit into the scheduled list time. Eur J Anaesthesiol. 2011; 28(7):493-501.

21. Tung A, Dexter F, Jakubczyk S, Glick DB. The limited value of sequencing cases based on their probability of cancellation. Anesth Analg. 2010;111(3):749-56.

22. Purzner T, Purzner J, Massicotte EM, Bernstein M. Outpatient brain tumor surgery and spinal decompression: a prospective study of 1003 patients. Neurosurgery. 2011;69(1):119-26; discussion 126-7.

23. Boulton $\mathrm{M}$, Bernstein $\mathrm{M}$. Outpatient brain tumor surgery: innovation in surgical neurooncology. J Neurosurg. 2008;108 (4):649-54

24. Carrabba G, Venkatraghavan L, Bernstein M. Day surgery awake craniotomy for removing brain tumours: technical note describing a simple protocol. Minim Invasive Neurosurg. 2008; 51(4):208-10.

25. Oakley J. Surgeon report cards, clinical realities, and the quality of patient care. Monash Bioeth Rev. 2009;28(3):21.1-21.6.

26. Neil DA, Clarke S, Oakley JG. Public reporting of individual surgeon performance information: United Kingdom developments and Australian issues. Med J Aust. 2004; 181(5): 266-8.

27. Hasman A, Holm S. Accountability for reasonableness: opening the black box of process. Health Care Anal. 2005;13(4):261-73.

28. Reeleder D, Martin DK, Keresztes C, Singer PA. What do hospital decision-makers in Ontario, Canada, have to say about the fairness of priority setting in their institutions? BMC Health Serv Res. 2005;5(1):8.

29. Martin DK, Singer PA, Bernstein M. Access to intensive care unit beds for neurosurgery patients: a qualitative case study. J Neurol Neurosurg Psychiatry. 2003;74(9):1299-303.

30. Kapiriri L, Norheim OF, Martin DK. Fairness and accountability for reasonableness. Do the views of priority setting decision makers differ across health systems and levels of decision making? Soc Sci Med. 2009;68(4):766-73.

31. Maluka SO. Strengthening fairness, transparency and accountability in health care priority setting at district level in Tanzania. Glob Health Action. 2011; 4:10.3402/gha.v4i0.7829. Epub 2011 Nov 7.

32. Stafinski T, Menon D, McCabe C, Philippon DJ. To fund or not to fund: development of a decision-making framework for the coverage of new health technologies. Pharmacoeconomics. 2011;29(9):771-80.

33. Schlander M. The use of cost-effectiveness by the National Institute for Health and Clinical Excellence (NICE): no(t yet an) exemplar of a deliberative process. J Med Ethics. 2008;34(7): 534-9.

34. Cooper AB, Joglekar AS, Gibson J, Swota AH, Martin DK. Communication of bed allocation decisions in a critical care unit and accountability for reasonableness. BMC Health Serv Res. 2005;5:67.

35. Gibson JL, Martin DK, Singer PA. Priority setting in hospitals: fairness, inclusiveness, and the problem of institutional power differences. Soc Sci Med. 2005;61(11):2355-62.

36. Daniels N, Sabin JE. Accountability for reasonableness: an update. BMJ. 2008;337:a1850.

37. Ibrahim GM, Fallah A, Snead OC 3rd, et al. Ethical issues in surgical decision making concerning children with medically intractable epilepsy. Epilepsy Behav. 2011;22(2):154-7.

38. Ibrahim GM, Barry BW, Fallah A, et al. Inequities in access to pediatric epilepsy surgery: a bioethical framework. Neurosurg Focus. 2012;32(3):E2

39. Harris J. QALYfying the value of life. J Med Ethics. 1987;13(3): $117-23$

40. Harris J. Life: quality, value and justice. Health Policy. 1988;10(3): 259-66.

41. Gruskin S, Daniels N. Process is the point: justice and human rights: priority setting and fair deliberative process. Am J Public Health. 2008;98(9): 1573-7. 